\title{
Evaluation of dermal collagen stained with picrosirius red and examined under polarized light microscopy*
}

\author{
Polyana Galvão Bernardes Coelho ${ }^{1}$ \\ Lissandro Gonçalves Conceição ${ }^{1}$ \\ Sirley Adriana Ortiz Bedoya ${ }^{1,2}$
}

\author{
Maria Verônica de Souza ${ }^{1}$ \\ Marlene Isabel Vargas Viloria ${ }^{1}$
}

DOI: http:/ /dx.doi.org/10.1590/abd1806-4841.20187544

\begin{abstract}
The special picrosirius red staining highlights the natural birefringence of collagen fibers when exposed to polarized light. The results from birefringence allow to evaluate the organization of the collagen fibers in the tissues. The authors intend to elucidate all steps to obtain and capture images of histological sections stained with picrosirius red and evaluated under polarized light microscopy, as well as possible artefacts that may occur.
\end{abstract}

Keywords: Collagen; Microscopy, polarization; Skin

Collagen, the main dermal constituent, can be analyzed or quantified through different techniques such as immunohistochemistry, confocal microscopy, polymerase chain reaction (PCR) and multiple stains: Masson's trichrome, picrosirius red, Weigert-van Gieson stain, Verhoeff. ${ }^{1-7}$ Even though the staining methods are not considered highly specific as the techniques mentioned, they can be quickly performed and have a low cost. Thus, it is important to be aware of the limitations of each stain. In this study, we will approach the main steps used to capture images from histologic sections stained with picrosirius red and analyzed under polarized light microscopy.

The special dye picrosirius red has the ability to enhance the natural birefringence of the collagen when exposed to polarized light. Collagen type I would show a yellow-red color, while type III would be green. ${ }^{8}$ On the other hand, Lattouf et al. ${ }^{9}$ stated that this special stain highlights the configuration of the collagen and the heterogeneity of the direction of the fibers in the tissues, with no differentiation between the types (Figure 1).

Despite the advantages of the use of special stains, at present, it is difficult to obtain polarized images of the collagen in histologic sections with picrosirius red. In this context, the objective of this manuscript was to elucidate all steps to obtain photomicro- graphs highlighting the birefringence of the collagen, using intact skin from two different species. The samples of skin used were canine and equine, from projects approved by the Ethics Committee in the Use of Animals (Ceua), Universidade Federal de Viçosa (UFV) under the records 78/2014 e 1/2017, respectively.

Histologic sections were stained with the commercial kit (Erviegas Instrumental Cirúrgico Ltda, São Paulo, SP, Brazil), and analyzed with an optical microscope Olympus BX-50 ${ }^{\circledR}$ (Japan), that was attached to the camera Olympus QColor 3 (Brazeiss Representações Ltda, São Paulo, SP, Brazil). The program for capture of images used was QCapture Pro 6 (Version 6.0.0.605, Qimaging, Canada https://www.qimaging.com/support/downloads/qcappro60.php).

Light emits rays that are dispersed in all directions; when it is polarized, only rays of specific directions pass over the polarizers. For this to occur, it is necessary to adapt filters to the microscope. The first filter, located between the light source and the condenser, can rotate $360^{\circ}$. In the microscope Olympus BX-50 ${ }^{\circledR}$, the filter is the U-POT (polarizer of transmitted light, Olympus, Japan). ${ }^{10}$ The second filter, located between the revolving nosepiece and the observation tube, has a lower ability of rotation. For the microscope used, it is U-ANT (analyzer of transmitted light, Olympus, Japan). ${ }^{10}$

Received 15 August 2017.

Accepted 03 November 2017.

* Work conducted at the Department of Veterinary and the Laboratório de Associações Micorrízicas, Universidade Federal de Viçosa (UFV), Viçosa (MG), Brazil. Financial support: None.

Conflict of interest: None.

Department of Veterinary, Universidade Federal de Viçosa (UFV), Viçosa (MG), Brazil.

2 Scholarship holder of the Program Estudantes-Convênio de Pós-Graduação (PEC-PG), Coordenação de Aperfeiçoamento de Pessoal de Nível Superior (Capes) and Conselho Nacional de Desenvolvimento Científico e Tecnológico (CNPq) - Brazil.

MAILING ADDRESS:

Polyana Galvão Bernardes Coelho

E-mail: polyanagalvao@gmail.com

C2018 by Anais Brasileiros de Dermatologia 
It is important that the condenser and the iris diaphragm are open, allowing for the passage of light. In the same way, it is important to observe neutral density filters (ND6 and ND25) and the daylight blue filter (LBD): when present, LBD and ND6 should be open, while ND25 should remain closed.

The next step is to configure the program for image capture and the microscope light, since the field darkens with the addition of the polarizing filters, leading to a higher light requirement. In this study, the intensity of the light beam of the microscope used for analysis under polarized light was 11 . The program's configuration is related to capture balance (gain, gamma, offset) and to white balance [red (R); green $(\mathrm{G})$; blue (B)], and the variation found is associated to the tissue, the stain and the management of the polarized light. The program's values, as well as those used for canine and equine skin were: gain: 1, 1.850 and 2.330; gamma: $1.000,1.000$ and $1.000-1.110$; offset: $0,-531$ - -630 and -430 - -630; red: 1, $1.6-2$ and $1.8-2.0$; green: 1.23, $1.4-1.8$ and $1.6-1.8$; blue: $2.38,1.3$ and $1.3-2.605$, respectively.

The values used for standardization of the image capture program should aim to a very black background, and the colors red and green from the birefringence should be very bright. Figure 2 shows an example of how the adequate configuration of the program influences the final result of the image obtained. It is important to remember that it is necessary to calculate the program's light exposure every time the objective, the slide and the amount of light are changed.

After the filters are adapted to the microscope and the capture program is standardized, the fields should be focused under non-polarized light, and the polarization should be achieved by
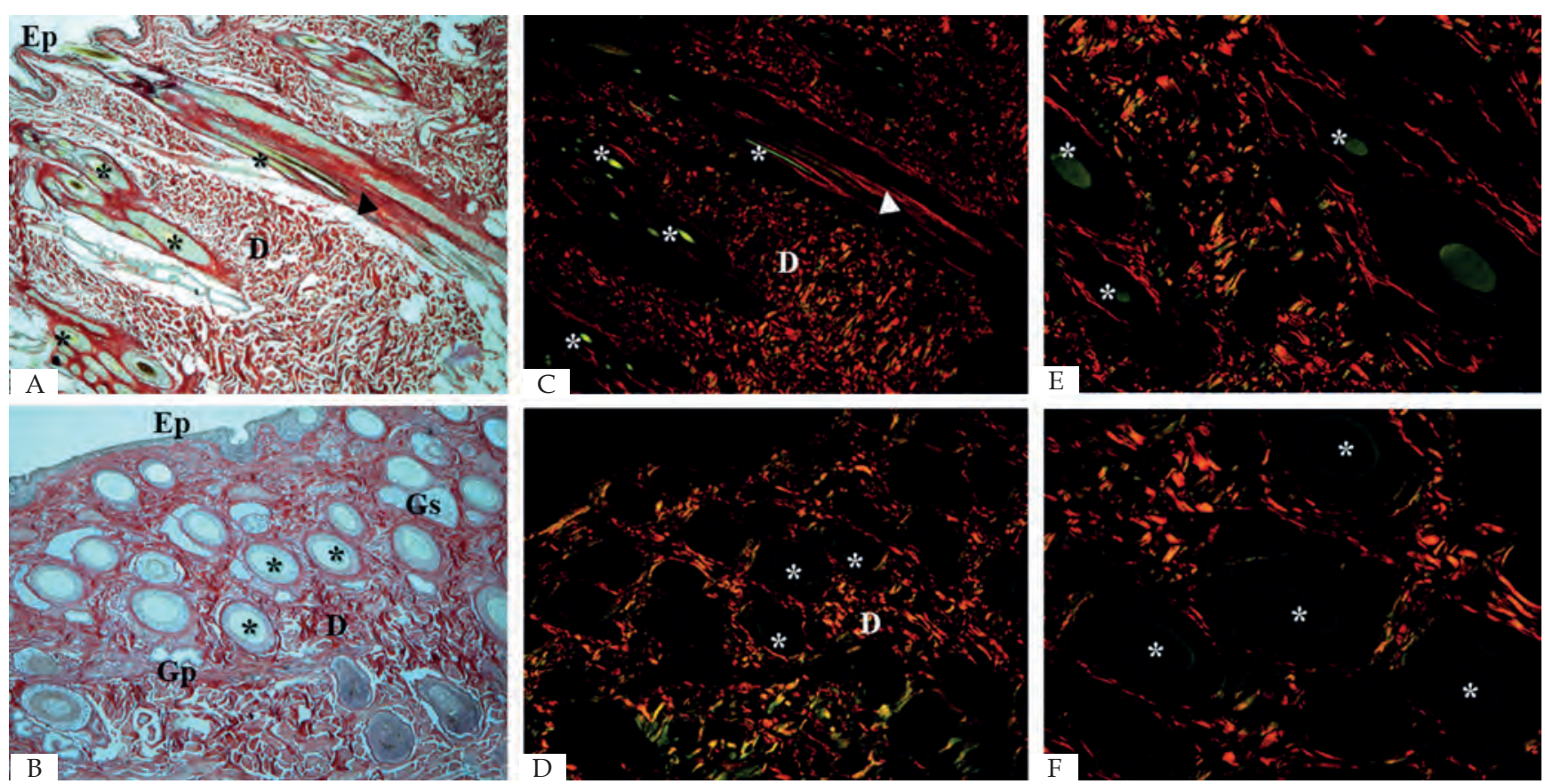

Figure 1: Photomicrographs of healthy canine $(\mathbf{A}, \mathbf{C}, \mathbf{E})$ and equine $(\mathbf{B}, \mathbf{D}, \mathbf{F})$ skin stained with picrosirius red, with a standardized program for image capture. Skin evaluated without polarized microscopy (A and B) and with polarized light, allowing for the observation of all its constituents (C and D) (x40). Birefringence of hair (green tones) and collagen (E and F) (x100). Ep: epidermis; D: dermis; Gs: sebaceous glands; Gp: sweat glands; *: hairs; arrowhead: arrector pili muscle
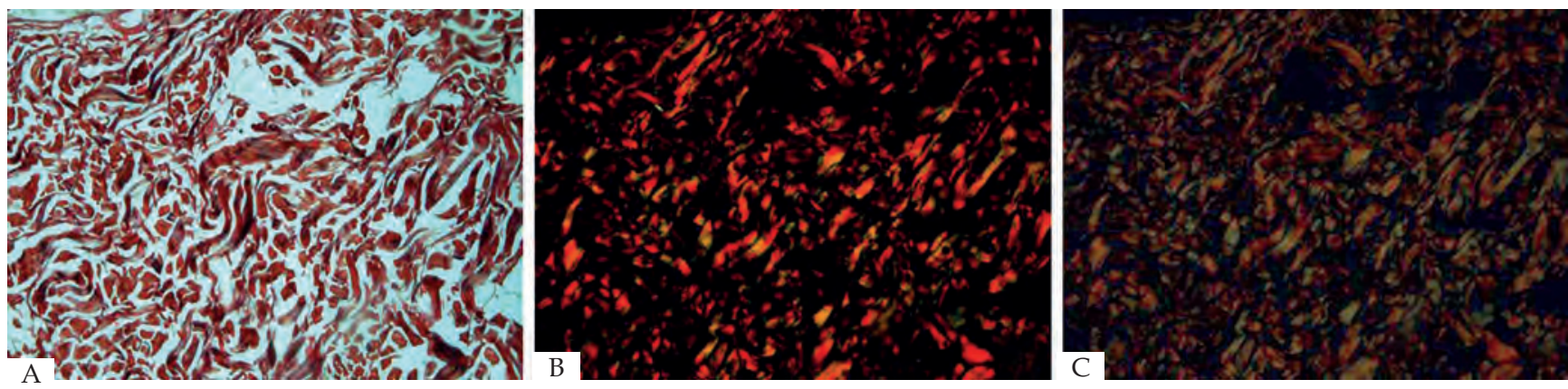

FiguRE 2: Photomicrographs of dog skin stained with picrosirius red and analyzed in three different ways. Microscopy with non-polarized light (A) and polarized light microscopy with the program QCapture Pro 6 standardized by the authors and with automatic configuration, respectively (B and C) (picrosirius red, $x 40$ ) 
turning the filter U-POT to an angle of $90^{\circ}$. During rotation, birefringence becomes evident and the background darkens until it becomes completely black (Figure 3 ). ${ }^{3}$ after polarization, the focus should once again be corrected to avoid loss of details.

The excessive rotation of the filter U-POT, above $90^{\circ}$, can alter the color of the collagen fibers with color inversion (green to red or red to green) or even loss of birefringence. To avoid this alteration, which can result in false results, we suggest that the rotation be performed gradually so as to follow the darkening of the field and the birefringence of the collagen fibers (Figure 4).

During the analysis of the images obtained from histologic sections stained with picrosirius red, some artefacts can be seen, such
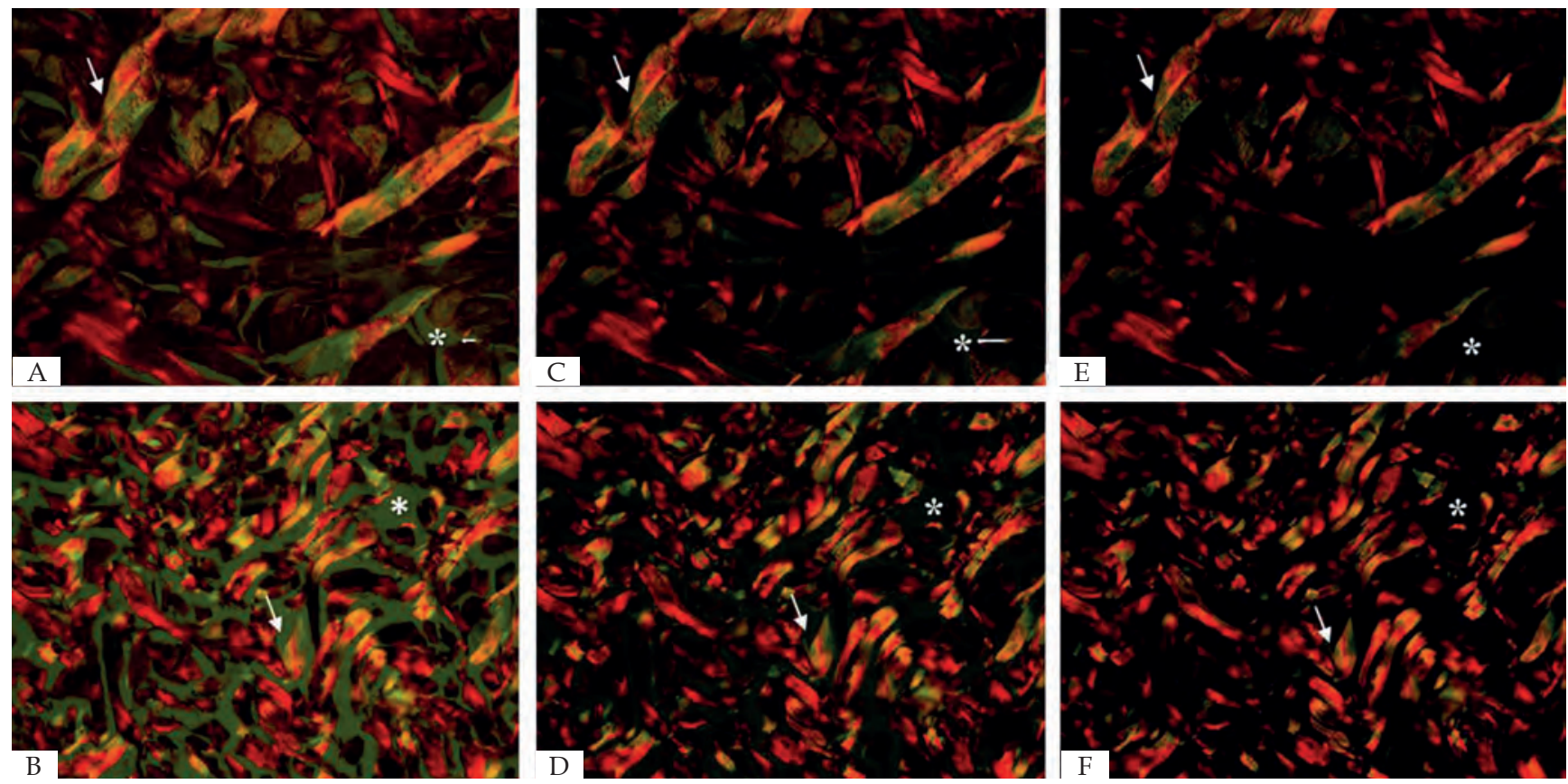

Figure 3: Photomicrographs of equine (A, C and E) and canine (B, D and F) skin sections during light polarization with the rotation of the filter U-POT. Approximate angle of $60^{\circ}(\mathrm{A}$ and $\mathrm{B}), 80^{\circ}(\mathrm{C}$ and $\mathrm{D})$ and $90^{\circ}(\mathrm{E}$ and $\mathrm{F})$. During this process, we can observe the gradual change in the background $\left({ }^{*}\right)$ and of the birefringence (arrow) (picrosirius red, $\times 200$ )
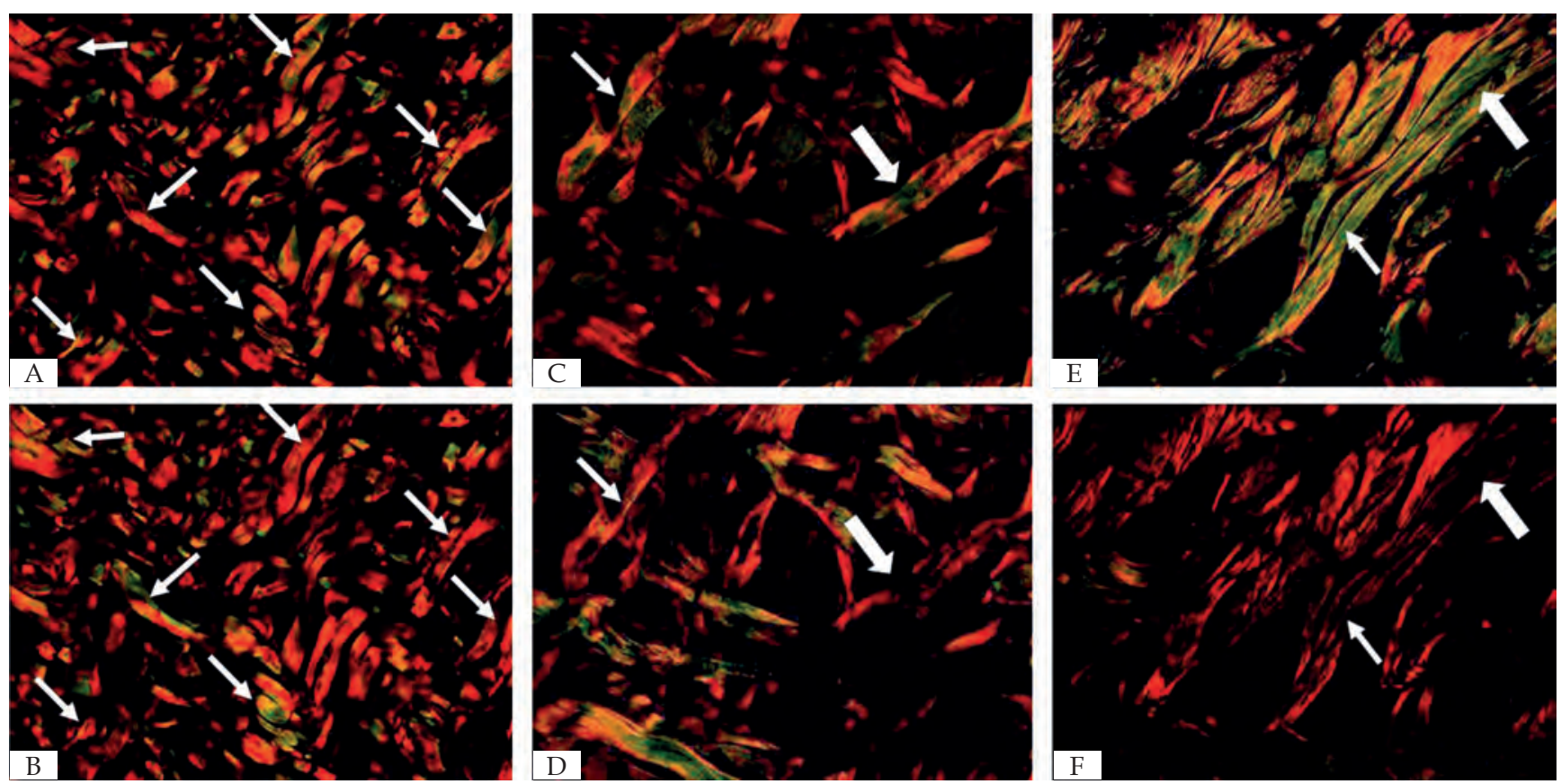

FiguRE 4: Photomicrographs showing inversion (fine arrow) and loss of birefringence (thick arrow) of the collagen fiber. Photomicrographs of canine (A and B) and equine (C, D, E and F) skin stained with picrosirius red obtained by polarization in a standardized program (x200). Note the change in the tone of the birefringence of the collagen fibers with a rotation above $90^{\circ}$ of the filter U-POT (B, D and F), whereas in the remaining images $(\mathrm{A}, \mathrm{C}$ and $\mathrm{E})$ the rotation corresponds to $90^{\circ}$ 

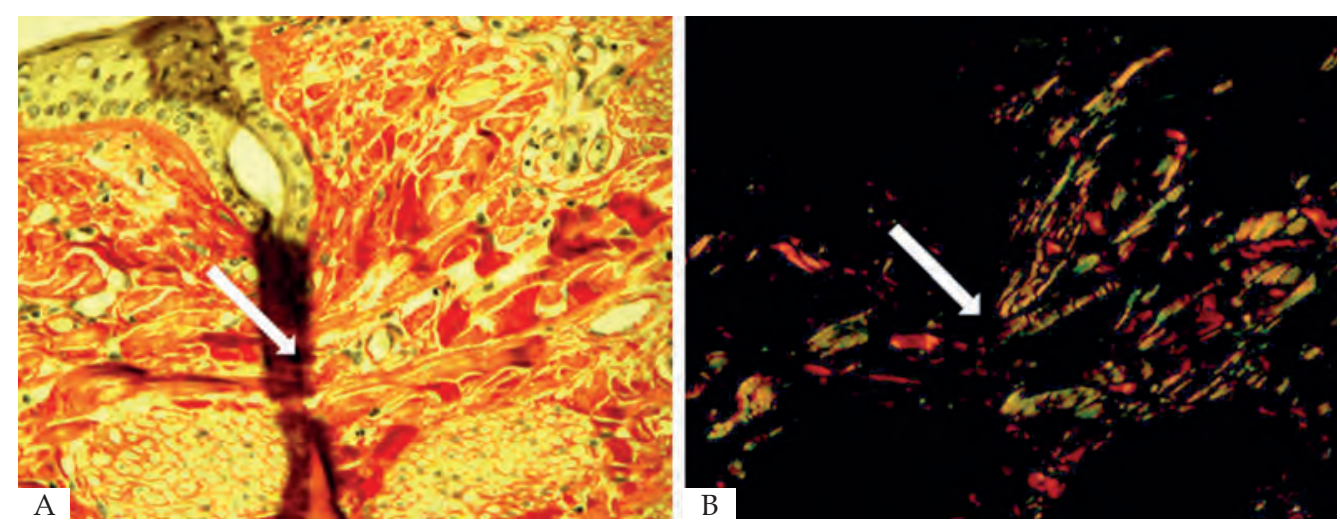

Figure 5: Folded histologic section in equine skin. Photomicrograph evaluated under polarization with an approximate rotation of $60^{\circ}(\mathrm{A})$ and $90^{\circ}(\mathrm{B})$ of the filter U-POT. Note the absence of birefringence (thick arrow) (picrosirius red, $\times 200$ )

as, for example, folds and granules of hematoxylin that can interfere with the final analysis if they become or not birefringent due to the overlap of section parts (Figure 5). Due to these possible alterations, we recommend avoiding fields with these artefacts that can lead to mistakes during the capture of the images.
Finally, the images obtained taking the suggestions in this manuscript into consideration can be analyzed in a reliable way by the morphometry technique or by programs of color segmentation, such as those used by Miot and Brianezi ${ }^{2}$ and by Bedoya et al. ${ }^{5}$

\section{REFERENCES}

1. Khavkin J, Ellis DA. Aging skin: histology, physiology, and pathology. Facial Plast Surg Clin North Am. 2011;19:229-34.

2. Miot HA, Brianezi G. Morphometric analysis of dermal collagen by color clusters segmentation. An Bras Dermatol. 2010;85:361-4.

3. Kamata H, Tsukasaki Y, Sakai T, Ikebe R, Wang J, Jeffers A, et al. KIF5A transports collagen vesicles of myofibroblasts during pleural fibrosis. Sci Rep. 2017;7:4556.

4. Souza MV, Pinto J0, Costa MBM, Alves M, Silva MO, Martinho KO, et al. Expressão gênica do colágeno em ferida cutânea de equinos tratada com plasma rico em plaquetas. Pesq Vet Bras. 2014;34:233-40.

5. Bedoya SAO, Conceição LG, Viloria MIV, Loures FH, Valente FL, Amorin RL, et al. Caracterização de colágenos tipos I e III no estroma do carcinoma de células escamosas cutâneo em cães. Arq Bras Med Vet Zootec. 2016;68:147-54.
6. Oriá RB, Ferreira FVA, Santana ÉN, Fernandes MR, Brito GAC. Study of agerelated changes in human skin using histomorphometric and autofluorescence approaches. An Bras Dermatol. 2003;78:425-34.

7. Ferreira E, Serakides R, Nunes VA, Gomes MG, Silva CM, Ocarino NM, et al. Morfologia e histoquímica da pele de ratas hipotireóideas castradas e não castradas. Arq Bras Med Vet Zootec. 2003;55:51-60.

8. Montes GS, Junqueira LC. The use of the Picrosirius-polarization method for the study of the biopathology of collagen. Mem Inst Oswaldo Cruz. 1991;86:1-11.

9. Lattouf R, Younes R, Lutomski D, Naaman N, Godeau G, Senni K, et al. Picrosirius Red staining: a useful tool to appraise collagen networks in normal and pathological tissues. J Histochem Cytochem. 2014;62:751-8.

10. Medic.ula.ve [Internet]. Armas DJN. La microscopía: herramienta para estudiar células y tejidos [acesso 02 Ago 2017]. Disponível em: http://www.medic.ula.ve/ histologia/anexos/microscopweb/MONOWEB/inicio.htm.
(iD) ORCID 0000-0002-3045-3241

(D) ORCID 0000-0001-8349-2597

\begin{tabular}{|c|c|}
\hline Polyana Galvão Bernardes Coelho & (D) ORCID $0000-0002-8145-8173$ \\
\hline Maria Verônica de Souza & (D) ORCID $0000-0002-2656-3333$ \\
\hline Lissandro Gonçalves Conceição & (iD) ORCID $0000-0001-7898-8766$ \\
\hline
\end{tabular}

